\title{
Relação entre resistência de linhagens tropicais de milho à podridão de espiga e ao acúmulo de fumonisinas provocados por Fusarium verticillioides
}

\author{
Adalgisa Thayne Munhoz ${ }^{1}$, Roberto Venceslau de Carvalho ${ }^{2}$, Pastora Josefina Querales ${ }^{1}$, Fabrício Packer Gonçalves ${ }^{3}$, \\ Luis Eduardo Aranha Camargo ${ }^{1}$
}

${ }^{1}$ Departamento de Fitopatologia e Nematologia, Escola Superior de Agricultura “Luiz de Queiroz", Cx. Postal 9, 13418-900, Piracicaba-SP; ${ }^{2}$ Dow AgroSciences Industrial Ltda. Jardinópolis-SP. Rod. Anhaguera, Km 344, Zona Rural; ${ }^{3}$ Instituto Agronômico do Paraná Curitiba-PR, CEP $80630-900$ Autora para correspondência: Adalgisa Thayne Munhoz(thaynemunhoz@hotmail.com)

Data de chegada: 17/12/2013. Aceito para publicação em: 23/03/2015.

$10.1590 / 0100-5405 / 1962$

\section{RESUMO}

Munhoz, A.T.; Carvalho, R.V.; Querales, P.J.; Gonçalves, F.P.; Camargo, L.E.A. Relação entre resistência de linhagens tropicais de milho à podridão de espiga e ao acúmulo de fumonisinas provocados por Fusarium verticillioides. Summa Phytopathologica, v.41, n.2, p.144-148, 2015.

A infecção de grãos de milho por Fusarium verticillioides, agente causal da podridão da espiga, pode resultar na produção de micotoxinas do grupo das fumonisinas. A resistência genética é a forma de controle mais eficiente dessa enfermidade. Assim, o objetivo do trabalho foi buscar fontes de resistência em linhagens de milho tropical à $F$. verticillioides e à produção de fumonisinas. Seis linhagens tropicais de milho, três, pré-classificadas como resistentes e três, pré-classificadas como suscetíveis à $F$. verticillioides, foram submetidas à inoculação do patógeno e posteriormente, avaliadas quanto à severidade da podridão de espiga, incidência de grãos sintomáticos e concentração de fumonisinas. Os resultados mostraram que as linhagens R1 e R3 apresentaram alta resistência à infecção do patógeno. No entanto, apenas a R3 foi resistente ao acúmulo de fumonisinas. Dessa forma, sugere-se que a ausência de relação entre intensidade da doença e níveis de fumonisinas seja fator inerente desse patossistema. Assim, não é possível assegurar que grãos assintomáticos quanto à infecção por $F$. verticillioides, estejam livres de contaminação por fumonisinas.

Palavras-chave: Fusarium verticillioides, Micotoxinas, Podridão da espiga

\section{ABSTRACT}

Munhoz, A.T.; Carvalho, R.V.; Querales, P.J.; Gonçalves, F.P.; Camargo, L.E.A. Relationship between resistance of tropical maize inbred lines for resistance to ear rot and fumonisins accumulation caused by Fusarium verticillioides. Summa Phytopathologica, v.41, n.2, p.144-148, 2015.

Maize infection by Fusarium verticillioides, the causal agent of Fusarium ear rot, can result in the production of mycotoxins of the fumonisin group. Genetic resistance is the most effective way to control this disease. Thus, the aim of this study was to evaluate tropical maize inbred lines as potential sources of resistance to $F$. verticillioides and production of fumonisins. Six maize inbred lines, three previously classified as resistant and three as susceptible to $F$. verticillioides, were inoculated with the pathogen and subsequently evaluated for ear rot severity, incidence of symptomatic grain and fumonisin concentration. Results showed that the lines R1 and R3 exhibited high resistance to the pathogen infection. However, only R3 was resistant to the accumulation of fumonisins. Therefore, it is suggested that absence of relationship between disease intensity and fumonisin production is inherent to this pathosystem. Thus, asymptomatic grains infected by $F$. verticillioides cannot be ensured to be free of contamination by fumonisins.

Additional keywords: Fusarium verticillioides, Mycotoxins, Ear rot

Espécies do gênero Fusarium são frequentemente associadas à cultura do milho, sendo Fusarium verticillioides (Saccardo) Nirenberg, (teleomorfo: Gibberella moniliformis) (Wineland), o principal responsável pela podridão rosada da espiga e de grãos e produção de fumonisinas em regiões de clima tropical $(11,27)$. As fumonisinas são micotoxinas comuns a alimentos e rações a base de milho $(21,28)$. Os principais membros desta classe são fumonisina $\mathrm{B}_{1}\left(\mathrm{FB}_{1}\right), \mathrm{FB} 2 \mathrm{e}$ FB3. Toxicoses causadas por fumonisinas, especialmente $\mathrm{FB}_{1}$, são consideradas um problema global devido aos seus efeitos danosos à saúde animal. Essas toxinas provocam leucoencefalomalácia (amolecimento e cavitações na substância branca do cérebro) em cavalos e coelhos (22); inchaço e edema pulmonar em suínos (8) e câncer hepático em roedores (7). Em humanos, em algumas regiões da África do Sul verificou-se uma correlação muito alta entre câncer de esôfago e consumo de grãos com elevados teores de fumonisinas (17).
Devido aos problemas acarretados por esta classe de toxina, órgãos internacionais como o FDA (Food and Drug Administration - EUA) e União Européia estabeleceram limites máximos de concentração de fumonisinas no milho destinado a produção de alimentos e rações (5). No Brasil, a Agência Nacional de Vigilância Sanitária (ANVISA) estabeleceu limites máximos permitidos de concentração de fumonisinas em milho de pipoca e para alimentos, a base de milho, destinados a alimentação infantil (9). AANVISA ainda estabeleceu que até $1^{\circ}$ de janeiro de 2014, milho em grão para posterior processamento poderá apresentar no máximo $5 \mu \mathrm{g} / \mathrm{g}$ de fumonisinas e até $1^{\circ}$ de janeiro de 2016, os limites estabelecidos de teor máximo de fumonisinas em farinha de milho, creme de milho, fubá, flocos, canjica, canjiquinha será de $1,5 \mu \mathrm{g} / \mathrm{g}$ e, de $1 \mu \mathrm{g} / \mathrm{g}$ de amido de milho e outros produtos à base de milho (9).

$\mathrm{O}$ regulamento adotado pela ANVISA representa uma importante 
medida para assegurar a qualidade de alimentos e rações, uma vez que existem trabalhos demonstrando os altos níveis de fumonisinas presentes no milho brasileiro destinados ao consumo humano e animal $(2,13)$. No entanto, em regiões de clima tropical como Brasil, Argentina e África do Sul há uma carência em pesquisas que visem a resistência desta cultura à infecção causada por Fusarium verticillioides e ao acúmulo de fumonisinas $(1,23)$, culminando em um limitado número de genótipos resistentes tanto à infecção do patógeno como ao acúmulo da micotoxina $(1,26)$.

Para o sucesso do estabelecimento de padrões de qualidade, de alimentos e rações, nas regiões tropicais é necessário identificar fontes de resistência ao patógeno e à produção de fumonisinas em germoplasmas de milho tropical. Dessa forma, o objetivo do trabalho foi avaliar os níveis de resistência a podridão de espiga e ao acúmulo de fumonisinas provocados por Fusarium veriticillioides dentre linhagens de milho tropical.

\section{MATERIAL E MÉTODOS}

\section{Delineamento Experimental}

O experimento a campo foi conduzido no município de

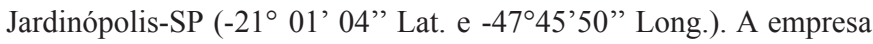
Dow AgroSciences Sementes e Biotecnologia Ltda. cedeu de seu banco de germoplasma, três linhagens tropicais de milho pré-classificadas como resistentes (linhagens R1, R2 e R3) e três pré-classificadas como suscetíveis (linhagens S1, S2 e S3) a podridão da espiga. Plantas das linhagens foram submetidas à inoculação artificial com isolados de $F$. verticillioides potencialmente toxigênicos. O delineamento foi em blocos ao acaso, formando seis tratamentos: inoculação em três linhagens resistentes e em três suscetíveis. A parcela experimental contou com seis repetições por tratamento, representadas por seis linhas de 20 plantas cada, espaçadas a $0,76 \mathrm{~m}$. O experimento foi repetido uma vez, sendo o primeiro realizado em 2007 e o segundo em 2008. O primeiro plantio foi realizado em 27 de novembro de 2007 e o segundo em abril de 2008. Os dados climáticos da região durante a condução dos experimentos foram obtidos na estação metereológica da própria estação.
Inoculação de $\boldsymbol{F}$. verticillioides

O inóculo foi constituído por mistura de conídeos de dez isolados caracterizados como $F$. verticillioides e com potencial toxigênico. A caracterização foi feita com base em reações de PCR utilizando iniciadores específicos para a espécie (16) e iniciadores para o potencial toxigênico, inferido pela presença do gene $F U M-5$ (4), e a confirmação realizada através da quantificação de produção de fumonisiana in vitro (25) (Tabela 1).

A inoculação ocorreu entre o sétimo e o décimo dia após o início do florescimento, período de maior suscetibilidade a infecção (18), através da pulverização dos estigmas com $2 \mathrm{ml}$ de uma suspensão de $10^{6}$ conídios $/ \mathrm{ml}$. Após a inoculação as panículas foram mantidas em câmara úmida por 48 horas.

\section{Avaliação da severidade da doença e incidência de grãos sintomáticos \\ Após quatro meses da semeadura foram realizadas avaliações da severidade de podridão da espiga e da incidência de grãos sintomáticos. A severidade foi avaliada por uma escala diagramática que estima a porcentagem da área da espiga com sintomas de podridão, caracterizados pela cobertura com micélio de coloração branco a róseo e pela presença de grãos escurecidos e/ou com estrias brancas no pericarpo. Essa escala compreende sete notas, sendo $1=0 \%$ - área da espiga sem sintomas, $2=1$ a $3 \%, 3=4$ a $10 \%, 4=11$ a $25 \%, 5=$ 26 a $50 \%, 6=51$ a $75 \%$ e $7=76$ a $100 \%$ de área da espiga exibindo sintomas visíveis de infecção $(1,20)$. Após a avaliação da severidade, as dez espigas avaliadas, em cada repetição de cada tratamento, foram ensacadas separadamente e secas por ar quente até os grãos atingirem aproximadamente $14 \%$ de umidade. As espigas foram debulhadas e os grãos misturados. A incidência de grãos sintomáticos foi avaliada em 200 grãos aleatoriamente coletados dessa mistura.}

\section{Quantificação de níveis de fumonisinas}

A quantificação de fumonisinas foi feita através do método de ELISA competitivo $(1,11)$ com o kit Myco Fumonisin ${ }^{\mathrm{TM}}$ (Strategic Diagnostics Inc., E.U.A.). Esse teste é calibrado para detectar uma mistura de fumonisinas $\mathrm{B}_{1}, \mathrm{~B}_{2}$ e $\mathrm{B}_{3}$ na razão 5:2:1, respectivamente. As amostras foram compostas por grãos colhidos de dez espigas por

Tabela 1. Identificação dos isolados de Fusarium verticillioides utilizados na inoculação artificial

\begin{tabular}{|c|c|c|c|c|}
\hline \multirow{3}{*}{ Isolado } & \multicolumn{3}{|c|}{ PCR (espécie- específico) } & \multirow[b]{2}{*}{ PCR (Gene $F U M-5$ ) } \\
\hline & Local & & nonisinas* & \\
\hline & Cidade/Estado & (Ver1R/Ver2F) & $\mu \mathrm{g} / \mathrm{g}$ & (Fum 5F/Fum 5R)** \\
\hline LGM FUS 003 & Tangará/Santa Catarina & + & 2,2 & + \\
\hline LGM FUS 017 & Mamborê/ Paraná & + & 9,1 & + \\
\hline LGM FUS 029 & Boa Esperança/Minas Gerais & + & 17,2 & + \\
\hline LGM FUS 037 & Machado/ Minas Gerais & + & 3,9 & + \\
\hline LGM FUS 105 & Tangará/Santa Catarina & + & 9,9 & + \\
\hline LGM FUS 113 & Cristalina/ Goias & + & 5,8 & + \\
\hline LGM FUS 117 & Unaí/ Minas Gerais & + & 8,1 & + \\
\hline LGM FUS 156 & Londrina/Paraná & + & 10,9 & + \\
\hline LGM FUS 169 & Rondonópolis/ Mato Grosso & + & 6,2 & + \\
\hline LGM FUS 185 & Maracaí/São Paulo & + & $>20$ & + \\
\hline
\end{tabular}

*Níveis de fumonisinas produzidos in vitro e quantificados através de ensaio de Elisa Competitivo, utilizando o Kit Myco Fumonisin (Strategy Diagnostics Inc. EUA)

** Iniciadores específicos para o gene FUM 5, relacionado à produção de fumonisinas (4).

+ reação de PCR positiva para os iniciadores utilizados. 
repetição de cada tratamento, de forma que, para cada tratamento (linhagens suscetíveis e resistentes) foram realizadas três análises separadas, (uma análise para cada repetição). Os testes de ELISA foram realizados em duplicata para cada amostra. O primeiro passo para essa análise consistiu na moagem das amostras a 20 mesh e, após mistura para homogeneização, uma sub-amostra de $500 \mathrm{~g}$ foi separada e, a partir desta, uma porção de $20 \mathrm{~g}$ foi pesada em erlenmeyers e utilizada para a extração das toxinas. O material moído foi suspenso em $100 \mathrm{~mL}$ de uma solução de metanol $70 \%$. Em seguida, foi agitado em agitador orbital a $28 \mathrm{rpm}$ por 25 minutos e decantado por 2 a 3 minutos. Quinze mililitros do extrato foram filtrados com filtro tipo Whatman ${ }^{\circledR} \# 1$ e recolhidos em tubo falcon de $50 \mathrm{~mL}$. Cinquenta microlitros do filtrado foram transferidos para poços de placa ELISA. O processamento deu-se conforme instruções do fabricante (Strategic Diagnostics Inc., E.U.A.). As leituras foram realizadas em aparelho Expert Plus (Asys Hitech $\mathrm{GmbH}$, Áustria) com filtro de $650 \mathrm{~nm}$.

\section{Análises Estatísticas}

Os valores de severidade e concentração de fumonisinas foram transformados pela equação $\sqrt{x}+3$ e os valores de incidência de grãos sintomáticos pela equação $\sqrt{ } \mathrm{P} / 100$ a fim de normalizar os resíduos. Os dados foram submetidos a ANOVA e as médias comparadas pelo teste de Tukey $(\mathrm{p}=0,05)$. O conjunto de todos os dados de cada uma das variáveis analisadas foi submetido a análise de regressão linear, sendo concentração de fumonisinas a variável dependente e incidência de grãos com sintomas e severidade da espiga as variáveis independentes.

\section{RESULTADOS E DISCUSSÃO}

No primeiro ano foram analisadas 336 espigas para a resistência a infecção causada por $F$. verticillioides. Nesse ano, a temperatura média na área experimental foi de $24,3{ }^{\circ} \mathrm{C}$ ( Tmin. $14,8^{\circ} \mathrm{C}$ e Tmáx. $\left.35,2^{\circ} \mathrm{C}\right)$ e a umidade relativa de $80 \%$ (Umin. $27,4 \%$ e Umáx. $100 \%$ ). No segundo ano, 517 espigas das mesmas linhagens foram analisadas, com temperatura média na área experimental de $21^{\circ} \mathrm{C}\left(\right.$ Tmin. $7,3^{\circ} \mathrm{C}$ e Tmáx. $33,1^{\circ} \mathrm{C}$ ) e a umidade relativa de $66 \%$ (Umin. $23 \%$ e Umáx. $100 \%$ ).

No primeiro ano, somente a linhagem R1 apresentou valores de severidade de podridão da espiga e incidência de grãos sintomáticos significativamente inferiores às linhagens classificadas como suscetíveis (Tabela 2). No segundo ano, a severidade de podridão da espiga das linhagens R1 e R3 foram inferiores a das linhagens pré-classificadas como suscetíveis e a linhagem R1 foi a única que apresentou menor incidência de grãos sintomáticos em relação as demais linhagens (Tabela 2).

Os valores inferiores dos parâmetros severidade e incidência da doença observada na linhagem R1, em relação às linhagens consideradas suscetíveis, podem ser comparados aos valores de algumas linhagens e híbridos classificados como resistentes na África (1). Por outro lado, essa linhagem (R1) não apresentou a mesma resistência em relação à concentração de fumonisinas, sobretudo no segundo ensaio. Essa flutuação no acúmulo de fumonisinas entre linhagens de milho e até mesmo na mesma linhagem em diferentes safras pode ser devido ao processo de biossíntese da micotoxina ser influenciado pelo isolado do patógeno, hospedeiro e condições ambientais $(15,19)$.

A maior incidência de doença ocorreu no primeiro ano, fato que pode estar associado às condições ambientais, que favoreceram o desenvolvimento do fungo. Nesse ano foram observadas elevadas temperaturas e elevada umidade relativa, fatores que favorecem o desenvolvimento da doença $(12,17)$. Outros fatores, além do clima, também devem ser relacionados à incidência da doença no campo e acúmulo de fumonisinas, como a redução do ataque de insetos que culmina na redução da infecção de Fusarium verticillioides e níveis de fumonisinas (3).

Os níveis totais de fumonisinas diferiram significativamente apenas na linhagem R1, R3 e S1 entre os dois ensaios (Tabela 2). No primeiro, a concentração de fumonisinas foi significativamente inferior nas linhagens consideradas resistentes quando comparados às linhagens suscetíveis S1 e S2 (Tabela 2). No segundo ano, somente a linhagem R3 apresentou concentração de fumonisinas significativamente inferior às demais linhagens (suscetíveis e resistentes). Esses resultados podem ser comparados com outros trabalhos, onde foi observada alta variabilidade em linhagens na África do Sul (1) e híbridos de milho nos EUA (6).

A concentração de fumonisinas apresentou correlação significativa com a severidade de podridão da espiga e com a incidência de grãos sintomáticos (Figura 1). Embora significativo, a distribuição dos pontos é muito distante da linha de regressão. Isso caracteriza baixa relação entre as variáveis dependente (fumonisina) e independentes (severidade ou incidência). Além disso, a regressão foi significativa apenas quando os dados foram analisados em conjunto para os dois ensaios, ou seja, quando um maior número de dados foi utilizado (Figura 1). O mesmo ocorreu em estudos realizados na Nigéria (1) e em diferentes estados Americanos $(8,14)$. Esses resultados podem estar relacionados à, pelo menos, duas hipóteses: (i) parte dos sintomas causados na espiga foi

Tabela 2. Severidade de podridão na espiga, incidência de grãos sintomáticos e concentração de fumonisinas em linhagens de milho infectadas por Fusarium verticillioides através de infecção artificial realiazada nos anos de 2007 e 2008.



As diferenças entre os ensaios estão representadas por letras maiúsculas e as diferenças entre linhagens estão representadas por letras minúsculas

${ }^{\mathrm{x}}$ Severidade de podridão de espiga causada por $F$. verticillioides em espigas avaliadas durante a colheita através de uma escala de nota, onde $1=$ sem sintomas, $2=1$ a $3 \%, 3=4$ a $10 \%$, $4=11$ a $25 \%, 5=26$ a $50 \%, 6=51$ a $75 \%$ e $7=76$ a $100 \%$ de sintomas na espiga (20) 




Figura 1. Relação entre concentração de fumonisinas e incidência de grãos sintomáticos e severidade de podridão de espiga (A e B, respectivamente). Os dados obtidos de plantas de milho inoculadas com Fusarium verticillioides, no ano de 2007 (círculos cheios) e de 2008 (círculos vazios). A severidade da doença foi baseada em uma escala de notas, onde $1=$ sem infecção; $2=1$ a $3 \%$ de infecção; $3=4$ a $10 \% ; 4=11$ a $25 \% ; 5=26$ a $50 \% ; 6=51$ a $75 \%$ e $7=76$ a 100 de infecção na espiga e grãos. Cada símbolo representa dados obtidos de linhagens individuais de milho.

provocado por isolados diferentes dos inoculados de $F$. verticillioides não produtores de fumonisinas ou que produzem níveis abaixo do limite detectável (24) e (ii) a baixa relação entre intensidade da doença e níveis de fumonisinas seja fator inerente desse patossistema. Essa última hipótese pode ser reforçada por outros trabalhos, os quais sugerem que fatores genéticos que afetam a infecção no grão podem operar independentes daqueles que afetam a produção de fumonisinas (1), sendo explicado em parte, pela natureza quantitativa dessas duas características (17).

As linhagens R1 e R3 foram confirmadas como fontes de resistência a infecção por $F$. verticillioides, contudo, somente a R3 apresentou resistência a produção de fumonisinas. Assim, nesse patossistema, há pelo menos três interações possíveis entre sintomas e toxinas: (i) presença de sintomas nos grãos acompanhados de elevados teores de fumonisinas; (ii) presença de sintomas nos grãos com baixos teores de fumonisinas e (iii) produção de toxinas em grãos sem sintomas visíveis de infecção $(1,8,17)$. Desta forma, esforços devem ser direcionados na busca de material genético resistentes a ambos os parâmetros, uma vez que nem sempre há correlação entre infecção de grãos e níveis de fumonisinas $(5,10)$. No presente estudo foi observado que grãos assintomáticos a podridão rosada da espiga, não garantem a ausência de contaminação por fumonisinas ou níves abaixo dos limites máximos de tolerância (9).

No Brasil, esse foi o primeiro estudo, relacionando a intensidade da doença e níveis de fumonisinas em linhagens tropicais de milho, através da inoculação de isolados potencialmente toxigênicos. Nesse trabalho apenas uma linhagem tropical de milho (R3) foi identificada com resistência a podridão rosada da espiga e a produção de fumonisinas. Assim, os resultados mostraram a necessidade de selecionar genótipos em programas de melhoramento genético, para a resistência à podridão de espiga e à produção fumonisinas. Por esta razão, a obtenção de genótipos resistentes a podridão de espiga, incidência de grãos sintomáticos e produção de fumonisinas, culmina em uma tarefa mais laboriosa e demorada. Desta forma, práticas que dificultam o desenvolvimento do fungo como remoção de grãos sintomáticos e/ ou danificados durante o beneficiamento e armazenamento e teor de umidade abaixo de $18 \%$, representam uma medida adicional na redução dos níveis de fumonisina.

\section{AGRADECIMENTOS}

Os autores agradecem a Thais N. R. Jorge; a empresa Dow AgroSciences Sementes e Biotecnologia Ltda. por todo o suporte durante a condução e análises do trabalho; à Fundação de Amparo a Pesquisa do Estado de São Paulo (FAPESP) (n: 2007/51525-5) e ao Conselho Nacional de Desenvolvimento Científico e Tecnológico (CNPq) pelo financiamento do projeto.

\section{REFERÊNCIAS}

1. Afolabi, C.G.; Ojiambo, P.S.; Ekpo, E.J.A.; Menkir, A.; Bandyopadhyay, R. Evaluation of maize inbred lines for resistance to Fusarium ear rot and fumonisin accumulation in grain in tropical Africa. Plant Disease, Saint Paul, v. 91, n. 3, p. 279-286, 2007.

2. Almeida, A.; Fonseca, H.; Fancelli, A.L.; Direito, G.M.; Ortega, E.M.; Corrêa, B. Mycoflora and Fumonisin Contamination in Brazilian Corn from Sowing to Harvest. Journal of Agricultural and Food Chemistry, Easton, v.50, n.13, p. 3877-3882, 2002.

3. Blandino, M.; Reyneri, A.; Vanara, F.; Pascale, M.; Haidukowski, M.; Saporiti, M. Effect of sowing date and insecticide application against European corn borer (Lepidoptera: Crambidae) on fumonisin contamination in maize kernels. Crop Protection, Surrey, v.27, n.11, p. 1432-1436, 2008.

4. Bluhm, B.H.; Flaherty, J.E.; Cousin, M.A.; Woloshuk, C.P. Multiplex polymerase chain reaction assay for the differential detection of trichothecene and fumonisin producing species of Fusarium in cormeal. Journal of Food Protection, Des Moines, v. 65, n.12, p.1955-1961, 2002.

5. Butrón, A.; Santiago, R.; Mansilla, P.; Pintos-Varella, C.; Ordás, A.; Malvar, R.A. Maize (Zea mays L.) genetic factors for preventing fumonisin contamination. Journal of Agricultural and Food Chemistry, Easton, v.54, n.16, p.6113-6117, 2006.

6. Clements, M.J.; Kleinschmidt, C.E.; Maragos, C.M.; Pataky, J.K.; White, D.G. Evaluation of inoculation techniques for Fusarium era rot and fumonisin contamination of corn. Plant Disease, Saint Paul, v.87, n.2, p.147-153, 2003. 
7. Desjardins, A.E. Fusarium mycotoxins: chemistry, genetics and biology. Saint Paul: The American Phytopatological Society, 2006. 268 p.

8. Desjardins, A.E.; Plattener, R.D.; Lu, M.; Claflin, L.E. Distribuition of fumonisins in maize ears infected with strains of Fusarium moniliforme that differ in fumonisina production. Plant Disease, Saint Paul, v. 82, n.8, p.953-958, 1998.

9. BRASIL. Lei $n^{\circ} 7$, de 18 de fevereiro de 2011. Dispõe sobre limites máximos tolerados (LMT) para micotoxinas em alimentos. Diário Oficial da União (DOU), Brasília, no 37, p. 72-73, de 22 de fevereiro de 2011. Disponível em: $<$ http://www.in.gov.br/imprensa/visualiza/index.jsp?jo rnal $=1 \&$ pagina $=72 \&$ data $=22 / 02 / 2011>$ Acesso em 4 de março de 2012 .

10. Eller, M.S., Holland, J.B., Payne, G.A. Breeding for improved resistance to fumonisin contamination in maize. Toxin Reviews, New York, v.27, p.371-389, 2008.

11. Eller, M.S., G.A. Payne, and J.B. Holland. Selection for reduced Fusarium ear rot and fumonisin content in advanced backcross maize lines and their topcross hybrids. Crop Science, Madison, v.50, n.6, p.2249-2260, 2010.

12. Herrera, M.; Conchello, P.; Juan, T.; Estopanan, G.; Herrera, A.; Arino, A. Fumonisins concentrations in maize as affected by physico-chemical, environmental and agronomical conditions. Maydica, Bergamo, v.55, n.1, p.121-126, 2010.

13. Kawashima, L.M.; Soares, L.M.V. Incidência de fumonisina $B$, aflatoxinas $\mathrm{B}_{1}, \mathrm{~B}_{2}, \mathrm{G}_{1}$ e $\mathrm{G}_{2}$, ocratoxina A e zearalenona em produtos de milho. Ciência e Tecnologia de Alimentos, Campinas, v.26, n.3, p.516-521, 2006.

14. Kleinschmidt, C.E.; Clements, M.J.; Maragos, C.M.; Pataky, J.K.; White, D.G. Evaluation of food-grade dent corn hybrids for severity of Fusarium era rot and fumonisin accumulation in grain. Plant Disease, Saint Paul, v.89, n.3, p. 291-297, 2005.

15. Lanza, F.E.; Zambolim, L.; Costa, R.V.; Queiroz, V.A.V.; Silva, D.D.; Souza, A.G.C.; Figueiredo, J.E.F. Prevalence of fumonisin-producing Fusarium species in Brazilian corn grains. Crop Protection, Surrey, v. 65, p. 232-237, 2014.

16. Mulè, G.; Susca, A.; Stea, G.; Moretti, A. A species-specific PCR assay based on the calmodulin partial gene for identification of Fusarium verticillioides, F. proliferatum and $F$. subglutinans. European Journal of Plant Pathology, Dordrecht, v.110, n.5, p.495-502, 2004.

17. Munkvold, G.P.; Desjardins, A.E. Fumonisins in maize: can we reduce their occurrence? Plant Disease, Saint Paul, v. 81, n. 6, p. 556-565. 1997.

18. Munkvold, G. P.; Mcgee, D. C.; Carlton, W. M. Importance of different pathways for maize kernel infection byFusarium moniliforme. Phytopa- thology, Saint Paul, v. 87, n. 2, p. 209-217, 1997.

19. Picot, A., Barreau, C., Pinson-Gadais, L., Caron, D., Lannou, C., RichardForget, F. Factors of the Fusarium verticillioides - maize environment modulating fumonisin production. Critical Reviews in Microbiology, Cleveland, v. 36, p. 221-231, 2010.

20. Reid, L.M.; Nicol, R.W.; Ouellet, T.; Savard, M.; Miller, J.D.; Young, J.C.; Atewart, D.W.; Schaafsma, A.W. Interaction of Fusarium graminearum and $F$. moniliforme in maize ears: disease progress, fungal biomass, and mycotoxin accumulation. Phytopathology, Saint Paul, v. 89, n.11, p.10281037, 1999

21. Rheeder, J.P.; Marasas, W.F.O.; Vismer, H.F. Production of fumonisin analogs by Fusarium species. Applied and Environmental Microbiology, Washington, v.68, n.5, p.2101-2105, 2002.

22. Ross, P.F.; Rice, L.G.; Osweiler, G.D.; Nelson, P.E.; Richard, J.L.; WIlson, T.M. A review and update of animal toxicoses associated with fumonisin-contaminated feeds and production of fumonisins by Fusarium isolates. Mycopathologia, Den Haag, v.117, n.1, p.109-114,1992.

23. Sampietro, D.A.; Vattuone, M.A.; Presello, D.A. Fauguel, C.M.; Catala, C.A.N. The pericarp and its surface wax layer in maize kernels as resistance factors to fumonisin accumulation by Fusarium verticillioides. Crop Protection, Surrey, v. 28, n.2, p.196-200, 2009.

24. Sánchez-Rangel D, Sanjuan-Badillo A, Plasencia J. Fumonisin production by Fusarium verticillioides strains isolated from maize in México and development of a polymerase chain reaction to detect potential toxigenic strains in grains. Journal of Agricultural and Food Chemistry, Easton, v. 53, n.22, p.8565-8571, 2005.

25. Shim, W.; Woloshuk, C.P. Nitrogen repression of fumonisin B1 biosynthesis in Gibberella fujikuroi. FEMS Microbiology Letters. New York,v. 177, n.1, p.109-116, 1999.

26. Small I. M.; Flett B. C.; Marasas W. F. O.; Mcleod A.; Stander M. A.; Viljoen A. Resistance in maize inbred lines to Fusarium verticillioides and fumonisin accumulation in South Africa. Plant Disease, Saint Paul, v. 96, n.6, p.881-888, 2012.

27. Stumpf, R.; Dos Santos, L.B.; Silva, S.N.; Tessmann, D.J.; Ferreira, F.D.; Machinski Jr., M.; Del Ponte, E.M. Fusarium species and fumonisins associated with maize kernels produced in Rio Grande do Sul State for the 2008/09 and 2009/10 growing seasons. Brazilian Journal of Microbiology, São Paulo, v. 44, n.1, p.89-95. 2013.28. Vargas, E.A,; Preis, R.A.; Castro, Silva, C.M.G. Co-occurrence of aflatoxins B1, B2,G1, G2, zearalenone and fumonisin B1 in Brazilian corn. Food Additives and Contaminants, London, v. 18, n. 11, p. 981-986, 2001. 